retinal haemorrhage wasfound. No one can be attached to a general hospital for very long without quickly becoming cognizant of this fact, and it is one which might with advantage be more emphasized than it is in our textbooks. The case of tetanus is interesting. Of course it occurred many years ago, and although nothing is said either in the case records or in the post-mortem notes of there being any other wound to account for it than the wound of the eye, it is possible, in fact I should think it very probable, that some other focus of infection existed. There can be no doubt of the tetanus, our forefathers in the profession knew tetanus when they saw it, but I do not think that I can count this case definitely among the very few which have been recorded where the wound in the eye was the primary cause.

The prominence of the globes noted in all three cases of Graves' disease shows that those who maintain that the exophthalmos does not persist in these cases after death are incorrect.

I have to express my best thanks to Dr. Robert Donaldson, Curator of the museum and Pathologist to the Hospital, for permission to extract these notes from the records, and for much kindly help.

\title{
A SERIES OF ONE HUNDRED CASES OF CATARACT REMOVED UNDER A SUBCONJUNCTIVAL BRIDGE
}

\author{
BY THE Laté \\ Charles Killick, M.D., F.R.C.S. \\ BRADFORD
}

No one, I think, should have the temerity to lay down the law about the merits or drawbacks of any particular operation unless he has performed it a great number of times. As I have, in the course of a fairly long professional career, extracted some 1,500 cataracts, $\mathrm{I}$ am in a position to know something about my subject and may claim to be acquainted with its various difficulties and complications. There can hardly be one that I have not come up against, I must have committed every possible fault and perpetrated every blunder known to the ophthalmic surgeon, including inserting the knife with its cutting edge downwards on no less than three occasions, until at last I have entered upon the calm waters of efficiency I trust, so far at any rate as cataract extraction is concerned. - My practice has always been to make the incision with puncture and counter-puncture at the limbus, to include nearly 
half the cornea and to complete the section with a conjunctival flap of greater or less extent. The results have not on the whole been unsatisfactory and not much worse I hope than other people's, and yet for some time past I have altered my technique, and with very few exceptions, have done ail my extractions under a subconjunctival bridge. Two main factors have influenced me in making the change, first a careful perusal of Terrien's description of the method which you will find in his excellent and recently published edition of "La Chirurgie des Yeux et de ses Annexes"; for it had somehow never occurred to me before that to convert my conjunctival flap into a bridge it was only necessary to make it a little larger and abstain from cutting it through when withdrawing the knife. The second was that I had had two patients, both of whom had a terrible loss of vitreous, ending in the one case in haemorrhage and total loss of the eye, and in the other in very poor vision. These cases, coming as they did almost on the top of one another, made me wonder whether subconjunctival extraction, although it might be more difficult, would not tend to prevent, or at any rate lessen, the danger of this undesirable complication.

Extraction under a subconjunctival bridge is no new device; in 1855 Desmarres strongly advocated it in the second edition of his book "Les Maladies des Yeux," and a full description is given, illustrated by some admirable drawings. Why the method fell so completely into oblivion, and was in fact abandoned by the master himself, after a short trial, in favour of a limbal incision reinforced by a conjunctival flap, fills me with surprise as its advantages are many and its difficulties, as I hope to show, very few. One of the reasons, perhaps, why Desmarres came to dislike the procedure was on account of haemorrhage from the conjunctiva, which he states may be troublesome. If this is a reason it would not hold good to-day owing to the discovery and use of adrenalin. A much more serious difficulty as I have found out by experience, is that the delivery of the lens is sometimes less easy to effect. It was not until nearly fifty years later that Vacher in 1899, and Pansier in 1898, working independently, again gave the method a trial, the former publishing a series of forty, and later still eighty cases, but his work only met with a lukewarm reception. Pansier, who at first was ignorant of Desmarres' original work, published his first list of sixty cases in 1899, and two years afterwards, reported that in the last 160 cases done in this way he had had only one case of sepsis, in a patient with diabetes and dacryocystitis, and in only one other case had he been compelled to divide the bridge. More recently still the method has had its advocates in Bajardi, Lundsgaard and Cridland. 
Operating, of course, long before the introduction of local anaesthesia Desmarres recommended the procedure chiefly because it did away with the danger of excessive gaping of the wound and the turning over or "renversement" of the corneal flap, which is liable to occur when there is an excessive escape of vitreous. $\mathrm{He}$ admits that his operations were limited in number, but that no accident had occurred capable of compromising vision.

As his illustrations show, he made his conjunctival bridge of the same width and height which Terrien recommends, i.e., just about equal to a third of the total incision, the only difference being that a Beer's knife was used for making the section instead of the narrow cataract knife of the present day. He opened the capsule with the point while traversing the anterior chamber, a manoeuvre imitated by Pansier. So far I have not copied his example in this respect. Desmarres, moreover, after his first two or three operations, recommended that the section should be made downwards on account of the tendency for the eye to roll upward, and he states that the bridge is easier to make by so doing. But, the difficulty of operating before the days of cocain must have been tremendous, and since its introduction no one, I think, would deliberately prefer to make an inferior section. If the lateral buttonhole was too small he either enlarged it with scissors, or, as the only alternative, cut the bridge across, thus converting it into an ordinary conjunctival flap. His final judgment was that the method was difficult and called for considerable experience in the cataract operation. It was, however, the best means of preventing eversion of the cornea, and prolapse of iris.

The method I adapt is frankly copied from Terrien; the width of the bridge varies, it may sometimes be as large as a third of the whole incision, more rarely it may be merely a small tether about two millimetres broad, perhaps from about four to five millimetres on the average. As soon as the knife has completed the section it is turned backwards and made to glide beneath the conjunctiva for about six millimetres in fact as far as possible; the longer the bridge the easier the extraction and the broader it is the better as it ensures coaptation of the lips of the wound, an important point when performing simple extraction. As a practical point care must be taken when completing the bridge lest the edge of the knife should touch the speculum at the point where the latter rides beneath the upper lid, or its edge will be spoilt. It is just a little difficult to avoid doing this at first. The bridge is just as easy to fashion in those cases where preliminary iridectomy has been done. It is difficult to make it of adequate dimensions where the palpebral fissure is narrow, and this constitutes the principal contraindication to the method. 
The ordinary technique is then followed except that of course everything must be done subconjunctivally. If combined extraction is to be performed iridectomy must be situated laterally either to the inner or outer side of the bridge, everything must be done subconjunctivally. Terrien recommends the inner side, I prefer the inner for the right eye and the outer for the left eye. Aesthetically, perhaps, the appearance is not quite so good as when the coloboma is in the usual position, but it is covered by the upper lid and need not be large, indeed, the less iris excised the better. In selected cases simple extraction may be preferred, in my series there are fifteen, marred, however, by one small prolapse of iris (No. 75). In this case, however, the patient made a good recovery with $6 / 18$ vision. Pansier reports one case of prolapse in fifty-two bridge extractions, and Vacher had not a single case in eighty. It is clear that the bridge is not an absolute safeguard against prolapse.

The capsule having been opened with a cystotome introduced through the lateral coloboma, the road is opened for extraction and now comes the real difficulty. The ease with which the lens is delivered varies with each case, it will depend partly on the kind of lens which is being dealt with; a ripe cataract with plenty of soft cortex can be removed to perfection, while another, which may be harder, stickier, or bulkier, may not escape so readily. A great deal depends upon the bridge, an extra millimetre in the height of this may make all the difference between easy birth and difficult labour. Sometimes a lens is hung up under the bridge and has to be assisted out with a spatula, sometimes it is just a question of manoeuvring. In four cases I had finally to divide the bridge in order to let the lens out; the more one gains in experience, however, the less likely it is that one has to resort to this expedient. As the cases in my series are not selected, but include every type and variety, the fact that the bridge had to be divided in only four per cent. shows that generally speaking it need only be resorted to very exceptionally.

According to Vacher and Bajardi, the exit of the lens may be promoted by inserting the spatula underneath the bridge and then depressing the upper lip of the wound. I have tried this and have found it to be unnecessary; Terrien states that simple pressure on the lower part of the cornea is sufficient. The technique will vary slightly according to the necessities of each case. Owing, however, to the protection and security which the bridge affords considerable pressure may be applied in cases of difficulty without fear of rupturing the hyaloid membrane as it is impossible for the lips of the wound to gape to a dangerous extent, or for the cornea to be forced backwards by a mass of prolapsed vitreous; once 
the lens has started on its journey all that is necessary is gentle guidance, and it must be kept moving in the right direction, obliquely upwards and laterally. I feel sure that the difficulty sometimes encountered in getting the lens to emerge has contributed more than anything else to bring the operation into disfavour. The last traces of cortex are possibly rather more difficult to remove by this method, but even in extraction in the ordinary way it is impossible in many cases to be absolutely certain that all has been got rid of, and until a safe and certain method of removing cataract and capsule together has been devised, and I am not quite convinced as yet that Barraquer's operation fulfils these conditions, the complication of after-cataract will always be with us. My series demonstrates, however, that I have had no very serious trouble with after-cataract as I have only had to needle fifteen times so far, and some of the discissions were not for after-cataract proper, but for wrinkling and folding of a transparent capsule coming on after a lapse of time.

The operation is brought to an end in the usual way by smoothing out any folds in the iris, atropin is instilled in cases where iridectomy has been done, and eserin if it has not. I generally apply a binocular dressing, but it is not essential, and many cases do perfectly well with a single pad. They walk back to bed except in cases of simple extraction. Pansier recommended a monocular dressing and asserts that it may be dispensed with after forty-eight hours. The patient need not even go to bed. One of his patients went back to his shop half an hour after extraction, and continued to serve his customers as if nothing had happened. My patients are dressed and the eye inspected after the first twentyfour hours. They get up on the third day, and not infrequently on the second, or even twenty-four hours after operation; glasses are given on the fifth, sixth, or seventh day.

Unfortunately, I cannot claim that the method is an absolute safeguard against infection. My series is marred by two cases of panophthalmitis. The first (No. 66), perhaps, is attributable to the patient herself. She was a diabetic, and I safely removed a cataract from her right eye a few months previously. She returned home, her health deteriorated in the interval, and I should have been wiser not to operate on the second eye. Extraction was followed by suppuration. The second case (No. 40), also occurred in a patient with sugar and albumen in the urine, so that it is hardly fair to criticize the method in either of these. Sugar was present in nine of the series, rather a large percentage. All made good recoveries, with the exception of the two mentioned. But, apart from this horrible accident the operation has distinct advantages, the most important of which is that the danger of 
loss of vitreous is almost if not quite eliminated. No loss of vitreous occurred in the series from beginning to end, and a significant point is that in three cases Nos. 36, 37, and 52 loss of vitreous had occurred in the case of the fellow eye, operated on by an experienced colleague. Once the bridge has been safely fashioned, the surgeon has complete control of the eye, however restless or stupid the patient may be, and Cridland remarks that so far as the patient is concerned it converts the operation from a big trial to a small one.

Serious iritis occurred in three cases with the formation of an inflammatory after-cataract in two (Nos. 50 and 59). Post-operative astigmatism is certainly no greater, although the contrary has been stated by Harrison Butler and others. Lastly, the operation has proved of distinct value in hospital patients, especially in men, who are of ten careless and apt to damage their eyes after operation. There were numerous cases of hyphaema in the series, but in no instance was the wound seriously disturbed, and all made good recoveries.

As an objection to the operation, Panas urges that the bridge constitutes a complication and makes it less easy. He is quite right in that, the method does demand a little more skill and experience than ordinary extraction. I do not recommend it until one has become thoroughly conversant with extraction in all its varieties. Harrison Butler has stated that it is wrong in principle as the closed pouch around the incision leads to delayed healing, to haemorrhage into the A.C., and to prolapse of iris. I can only say that so far I have not come up against these disadvantages. The one positive contraindication that I know of is, as before mentioned, a narrow palpebral fissure; in such a case it is impracticable to make an adequate bridge.

As Critchett says, however, we must be eclectic in our operations for cataract, and while I am not going to assert that it is the operation for choice in every case, I can only say that for the fully ripe cataract of the ordinary type it is almost ideal and I commend it to your notice with the fullest confidence.

\section{REFERENCES}

1. Terrien, F. - Chirurgie de l'Oeil et de ses Annexes.

2. Desmarres. - Les Maladies des Yeux. 2nd edition.

3. Vacher, C.-La Clin. Ophtal., 1899.

4. Pansier, P.-Annales d'Oculistique, 1901.

5. Bajardi, A.-Boll. della Acad. Med. di Genova, 1910.

6. Butler, T. Harrison-" Subconjunctival cataract extraction "-Trans. Ophthal. Soc., 1922. 
LIST OF CASES.

\begin{tabular}{|c|c|c|c|c|}
\hline No. & Name & Sex & Remarks & Vision \\
\hline 1 & C & M & & $6 / 36$ \\
\hline 2 & $\mathrm{H}$ & $M$ & Discission & $6 / 18$ \\
\hline 3 & $\mathbf{F}$ & $\mathbf{M}$ & & $6 / 12$ \\
\hline 4 & $\mathrm{~T}$ & $\mathrm{~F}$ & & $6 / 24$ \\
\hline 5 & $\mathrm{~K}$ & $\mathbf{F}$ & & $6 / 9$ \\
\hline 6 & $\mathbf{S}$ & $\mathbf{F}$ & Diabetes & $6 / 24$ \\
\hline 7 & $P$ & $\mathbf{M}$ & & $6 / 24$ \\
\hline $\begin{array}{l}8 \\
9\end{array}$ & $\begin{array}{l}\mathrm{D} \\
\mathrm{C}\end{array}$ & $\begin{array}{l}\mathbf{M} \\
\mathbf{M}\end{array}$ & Discission & $\begin{array}{l}\text { No record } \\
6 / 24\end{array}$ \\
\hline 10 & $\mathrm{~J}$ & $\mathbf{F}$ & & $6 / 9$ \\
\hline 11 & $\mathrm{~B}$ & $\mathbf{F}$ & Diabetes. Bridge divided & $6 / 24$ \\
\hline 12 & A & $\mathbf{F}$ & Myopia. Nebulae & $6 / 60$ \\
\hline 13 & $\mathrm{H}$ & $\mathbf{M}$ & & No record \\
\hline 14 & $\mathbf{T}$ & $\mathbf{F}$ & Simple. Discission & $6 / 18$ \\
\hline 15 & $\mathrm{~T}$. & $\mathbf{F}$ & Diabetes & $6 / 60$ \\
\hline $\begin{array}{l}16 \\
17\end{array}$ & $\begin{array}{l}\mathrm{W} \\
\mathrm{T}\end{array}$ & $\begin{array}{l}\mathbf{F} \\
\mathbf{M}\end{array}$ & & $\begin{array}{l}\cdot 6 / 24 \\
\text { No record }\end{array}$ \\
\hline 18 & W & $\mathrm{F}$ & & $6 / 18$ \\
\hline 19 & $\mathbf{M}$ & $\mathrm{F}$ & & $6 / 12$ \\
\hline 20 & $\mathbf{N}$ & $\mathbf{F}$ & & No record \\
\hline 21 & $\mathrm{H}$ & $\mathbf{F}$ & & $6 / 9$ \\
\hline 22 & A & $\mathrm{F}$ & & $6 / 24$ \\
\hline $\begin{array}{l}23 \\
24\end{array}$ & $\begin{array}{l}\mathrm{B} \\
\mathrm{H}\end{array}$ & $\begin{array}{l}\mathbf{F} \\
\mathbf{M}\end{array}$ & Diabetes. Bridge divided. Discission & $\begin{array}{l}6 / 18 \\
6 / 60\end{array}$ \\
\hline 25 & $\mathbf{P}$ & $\mathrm{F}$ & Iritis. After-cataract. Discission & \\
\hline 26 & $\mathrm{D}$ & $\mathrm{M}$ & & $6 / 18$ \\
\hline $\begin{array}{l}27 \\
28\end{array}$ & $\begin{array}{l}\mathbf{P} \\
\mathbf{R}\end{array}$ & $\begin{array}{l}\mathrm{M} \\
\mathrm{F}\end{array}$ & & $\begin{array}{l}6 / 36 \\
6 / 9\end{array}$ \\
\hline 29 & $\mathbf{P}$ & $\mathrm{E}$ & Feeble minded & \\
\hline 30 & $\mathrm{~W}$ & $\mathrm{~F}$ & Diabetes & No record \\
\hline 31 & B & $\mathbf{F}$ & & $6 / 12$ \\
\hline 32 & B & $\mathbf{F}$ & Discission & $6 / 12$ \\
\hline 33 & $\mathbf{F}$ & $\mathbf{F}$ & Discission & $6 / 6$ \\
\hline 34 & B & $\mathrm{F}$ & Discission & $6 / 18$ \\
\hline 35 & D & $\mathbf{M}$ & $\begin{array}{l}\text { Vitreous lost when other eye was operated upon. } \\
\text { Discission }\end{array}$ & $6 / 18$ \\
\hline 36 & $\mathbf{M}$ & $\mathbf{F}$ & Discission & $6 / 18$ \\
\hline 37 & $\mathbf{M}$ & $\mathbf{F}$ & Vitreous lost when first eye was operated upon & $6 / 18$ \\
\hline 38 & $\mathrm{~L}$ & $\mathbf{F}$ & Simple. Conical cornea. Discission & $6 / 24$ \\
\hline 39 & $\mathbf{S}$ & $\mathbf{M}$ & & $6 / 36$ \\
\hline 40 & C & $\mathbf{F}$ & Diabetes and albumen. Panophthalmitis & \\
\hline 41 & $\mathrm{C}$ & $\mathbf{M}$ & Optic atrophy & $6 / 60$ \\
\hline 42 & C & M & & $6 / 18$ \\
\hline 43 & $\mathbf{T}$ & $\mathbf{F}$ & Discission & $6 / 12$ \\
\hline 44 & $\mathrm{R}$ & $\mathbf{M}$ & Bridge divided & $6 / 12$ \\
\hline 45 & D & $\mathbf{M}$ & Simple. Discission & $6 / 9$ \\
\hline 46 & $\mathbf{F}$ & $\mathbf{F}$ & Discission & $6 / 24$ \\
\hline 47 & $\mathrm{~s}$ & $\mathrm{~F}$ & Simple. Discission & $6 / 9$ \\
\hline 48 & $\mathrm{~T}$ & $\mathbf{M}$ & Simple & $6 / 12$ \\
\hline 49 & $\mathrm{C}$ & $\mathbf{M}$ & For secondary cataract & \\
\hline 50 & $\mathbf{R}$ & $\mathbf{M}$ & Myopia & \\
\hline 51 & B & $\mathbf{F}$ & Iritis. After-cataract & \\
\hline 52 & B & $\mathbf{F}$ & Simple. Discission & $6 / 36$ \\
\hline 53 & B & $\mathbf{F}$ & Simple. Vitreous escaped at first operation & $6 / 24$ \\
\hline 54 & $\mathbf{H}$ & $\mathbf{F}$ & Myopia & \\
\hline 55 & $\mathrm{H}$ & $\mathbf{F}$ & & $6 / 18$ \\
\hline 56 & $\mathrm{~T}$ & $\mathbf{F}$ & Simple. Discission & $6 / 18$ \\
\hline
\end{tabular}


Series of One Hundred Cases of Cataract $32 \tau$

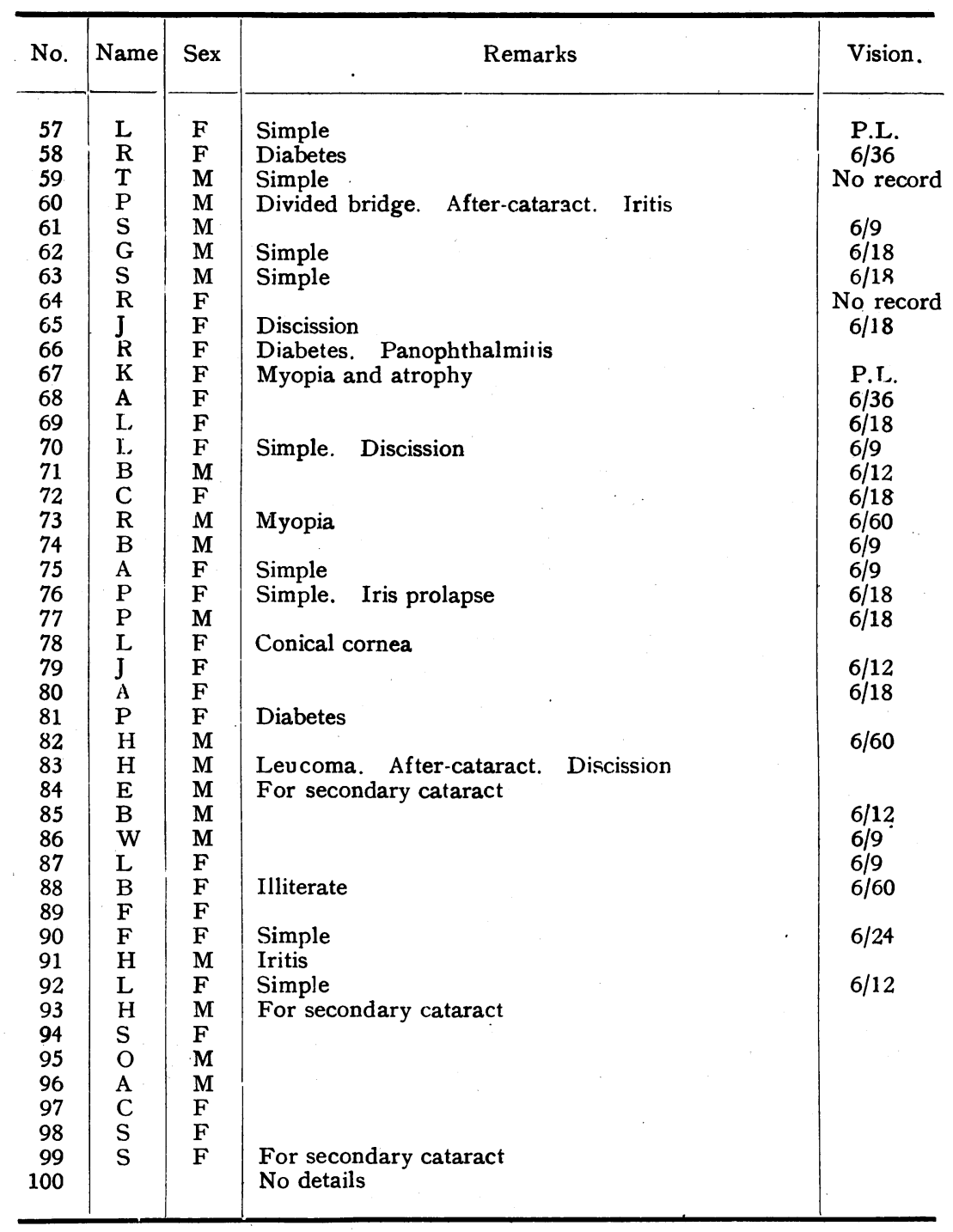

